\title{
Community Oncology and Rehabilitation Branch
}

National Cancer Institute

\section{Source}

National Cancer Institute. Community Oncology and Rehabilitation Branch. NCI

Thesaurus. Code C19280.

Part of the Division of Cancer Prevention. Develops programs to improve clinical oncology in community settings and coordinates community oncology program activities with the activities of other research programs of the National Cancer Program; Promotes interaction between community oncologists and regional or national clinical cooperative groups; Stimulates psychosocial and physical rehabilitation research; Develops and conducts research on the management of cancer pain; develops research in the area of supportive care for patients and families; Studies the impact of cancer control programs on the community; and Conducts preliminary Phase II cancer control) studies of education, attitudes, and behavior of physicians, nurses, and other health professionals to serve as the basis for subsequent cancer control studies. 